\title{
Chemotherapy-induced dynamic gene expression changes in vivo are prognostic in ovarian cancer
}

\author{
A Koussounadis ${ }^{1}$, S P Langdon ${ }^{2}$, D J Harrison ${ }^{3}$ and V A Smith ${ }^{*, 1}$ \\ ${ }^{1}$ School of Biology, Sir Harold Mitchell Building, University of St Andrews, St Andrews, Fife KY16 9TH, UK; ${ }^{2}$ Division of Pathology, \\ Institute of Genetics and Molecular Medicine, University of Edinburgh, Edinburgh EH4 2XU, UK and ${ }^{3}$ School of Medicine, \\ University of St Andrews, St Andrews, Fife KY16 9TF, UK
}

Background: The response of ovarian cancer patients to carboplatin and paclitaxel is variable, necessitating identification of biomarkers that can reliably predict drug sensitivity and resistance. In this study, we sought to identify dynamically controlled genes and pathways associated with drug response and its time dependence.

Methods: Gene expression was assessed for 14 days post-treatment with carboplatin or carboplatin-paclitaxel in xenografts from two ovarian cancer models: platinum-sensitive serous adenocarcinoma-derived OV1002 and a mixed clear cell/endometrioid carcinoma-derived HOX424 with reduced sensitivity to platinum.

Results: Tumour volume reduction was observed in both xenografts, but more dominantly in OV1002. Upregulated genes in OV1002 were involved in DNA repair, cell cycle and apoptosis, whereas downregulated genes were involved in oxygenconsuming metabolic processes and apoptosis control. Carboplatin-paclitaxel triggered a more comprehensive response than carboplatin only in both xenografts. In HOX424, apoptosis and cell cycle were upregulated, whereas Wnt signalling was inhibited. Genes downregulated after day 7 from both xenografts were predictive of overall survival. Overrepresented pathways were also predictive of outcome.

Conclusions: Late expressed genes are prognostic in ovarian tumours in a dynamic manner. This longitudinal gene expression study further elucidates chemotherapy response in two models, stressing the importance of delayed biomarker detection and guiding optimal timing of biopsies.

Current standard treatment for ovarian cancer consists of carboplatin with or without paclitaxel following surgery (Cannistra, 2004). Although the majority of patients initially respond to therapy, most eventually relapse whereas others are resistant to treatment at the outset (International Collaborative Ovarian Neoplasm Group, 2002). Thus, it is important to understand and define which patients are likely to be sensitive to treatment and who have resistant disease. In this study, we analysed gene expression changes after treatment in two ovarian cancer models with distinct chemotherapy response profiles over a period of 14 days. The OV1002 model is derived from high-grade serous adenocarcinoma and is platinum sensitive, whereas HOX424 is of clear cell/endometrioid carcinoma origin and has reduced responsiveness to platinum.

Our emphasis was on pathways rather than individual genes. Previous studies have evaluated the association of gene expression directly with outcome in clinical specimens (Helleman et al, 2006; Tothill et al, 2008; Crijns et al, 2009; Konstantinopoulos et al, 2011) and have predominantly sought to identify candidate genes that link with outcome. Other studies have evaluated the temporal impact of platinum on sensitive and resistant ovarian cancer cells in vitro with a view to identifying resistance mechanisms 
(Li et al, 2007); however, the cisplatin-treated isogenic cell lines were monitored for a limited period of $24 \mathrm{~h}$. Several genes have been found differentially expressed in ovarian cancer cell lines treated with platinum drugs or taxanes (Sherman-Baust et al, 2011). Helleman et al (2010) have used a panel of nine gene sets associated with platinum resistance to perform pathway analysis. Knowledge of the molecular mechanisms involved in drug response is essential to improve therapy and possibly reverse drug resistance (Shahzad et al, 2009).

The use of human ovarian cancer xenografts allows the analysis of drug treatment on temporal changes of gene expression in cancer tissue after treatment, a task not easily undertaken in patients. Comparison of models that are either chemosensitive or chemoresistant should help identify gene expression changes that are associated with response, and some of these genes are likely to be helpful to predict outcome after treatment. In this study, we used models with distinct response patterns to carboplatin and assessed their gene expression profiles after treatment with drugs. We identified time-related gene clusters and significant pathways with predictive value within independent clinical data sets.

\section{MATERIALS AND METHODS}

Xenografts. The OV1002 and HOX424 models were established at the Institute of Genetics and Molecular Medicine, University of Edinburgh, as previously described (Faratian et al, 2011). Adult female nu/nu mice were implanted subcutaneously with ovarian tumour fragments in the flanks and allowed to grow to $4-6 \mathrm{~mm}$ in diameter (over a period of $\sim 2$ months). Animals were at least 8 weeks old at the time of experimentation and were maintained in negative pressure isolators (La Calhene, Cambridge, UK). The mice were treated with carboplatin $\left(50 \mathrm{mg} \mathrm{kg}^{-1}\right)$, carboplatin $\left(50 \mathrm{mg} \mathrm{kg}^{-1}\right)+$ paclitaxel $\left(10 \mathrm{mg} \mathrm{kg}^{-1}\right)$ or were untreated. Drugs were given as a single injection via the intraperitoneal route in saline on day 0 . Tumour size was measured twice weekly using calipers and the volume calculated according to the formula $\pi / 6 \times$ length $\times$ width $^{2}$. Relative tumour volumes (RTV) were then calculated for each individual tumour by dividing the tumour volume on day $t(\mathrm{Vt})$ by the tumour volume on day $0(\mathrm{~V} 0)$. Treated xenografts were harvested on days 1, 2, 4, 7 and 14, and untreated controls on days $0,1,7$ and 14. A total of 101 xenografts were used, with 3-4 biological replicates per time point (except carboplatin-paclitaxel-treated HOX424 on day 2 that had 2 replicates; Supplementary Table 1, column D). Agreement between their expression levels was good as measured by the correlation coefficients $(r)$ among replicates of each condition (mean $r$ 95\% confidence interval 0.987-0.990, Supplementary Table 1, column E).

Gene expression profiling and analysis. Total RNA was prepared from 10 to $50 \mathrm{mg}$ of frozen tissue on the days of treatment, preincubated with RNAlater-ICE (Ambion, Austin, TX, USA) using the miRNeasy Mini kit (Qiagen, Hilden, Germany) and TissueRuptor (Qiagen) following the manufacturers' instructions. The RNA quality was checked by the RNA 6000 Nanoassay on the Agilent Bioanalyzer (Agilent Technologies, Santa Clara, CA, USA). All samples were divided into two identical aliquots for independent labelling and hybridisation. Total RNA for each sample $(0.5 \mathrm{mg})$ was amplified and biotinylated using the Illumina TotalPrep RNA Amplification Kit (Ambion) according to manufacturers' standard procedure. This consists of reverse transcription with an oligo(dT) primer bearing a $\mathrm{T} 7$ promoter using a reverse transcriptase (RT). The quality and quantity of cRNA in the samples was checked with an Agilent Bioanalyzer 2100 (Agilent Technologies), samples were diluted to $150 \mathrm{ng} \mathrm{ml}^{-1}$ and hybridised to Illumina HT-12 BeadChips in duplicate
(Illumina, San Diego, CA, USA). This Illumina platform was previously validated by $\mathrm{qPCR}$ in a breast cancer-derived xenograft study (Sims et al., 2012).

Analysis of microarray data. Illumina chips contained 47323 probes. Expression sets were processed using Bioconductor's lumi package (Du et al, 2008). The data set has been deposited to Gene Expression Omnibus (GEO) with accession number GSE49577. Bioconductor package limma (Smyth, 2005) was used for differential expression calculations. Treated samples from days 1 , 2, 4, 7 and 14 post-treatment were contrasted to pooled controls in each cell line. Significant genes had FDR adjusted $P$-values of $<0.05$. Differentially expressed genes were classified as early (days 1-4) and/or late (days 7 and 14), and as either transient (expressed significantly in one time point) or sustained (expressed significantly in at least two time points). Means of log-fold change values for each time point of differentially expressed genes were hierarchically clustered using Cluster 3.0 (Eisen et al, 1998) to identify genes with similar temporal profiles. Heatmaps were visualised using Bioconductor. Overrepresented KEGG (Kyoto encyclopedia of genes and genomes) pathways (Kanehisa et al, 2012) were identified using DAVID (Database for Annotation, Visualisation and Integrated Discovery) (Huang et al, 2009).

Hierarchical clustering and Kaplan-Meier survival analysis. Two clinical ovarian cancer gene expression data sets from GEO, GSE9891 (Tothill et al, 2008) and GSE3149 (Bild et al, 2006), were used to assess the prognostic capacity of dynamically changing genes in response to treatment (Supplementary Table 2). Clinical data, such as survival time and censoring information, were available for both data sets. Our hypothesis was that, if gene sets play crucial roles in tumour progression, then patients with different gene expression patterns of such gene sets may also have different overall survival (OS) and prognosis. For each cluster of differentially expressed genes from both treatments and models in our study, the corresponding genes were selected in the two clinical ovarian cancer data sets. Unsupervised hierarchical clustering was applied to expression values in the clinical data sets in order to separate tumour samples based on expression profiles, as described previously (Liu et al, 2008). The hierarchical clustering was divided at the highest level to produce two groups of tumour samples having the most broadly different gene expression profiles. Kaplan-Meier plots were graphed to visualise the difference in OS between these groups and, thus, the capacity of the gene set to discriminate favourable from poor prognosis patients. Log rank $P$-values were calculated to assess the statistical significance of the difference in survival probabilities between the two patient groups. Using the same methodology, sets of differentially expressed genes with distinct temporal expression profiles were tested, as well as genes in selected overrepresented pathways. To mitigate multiple testing issues, only significant pathways known to be involved in ovarian cancer were tested. Except where noted, all genes in an overrepresented pathway that were extant in the clinical data set (whether they had been differentially expressed in our data set or not) were used as the gene set.

\section{RESULTS}

Treatment with carboplatin or carboplatin-paclitaxel causes a reduction in tumour growth of ovarian cancer model xenografts. The effect of carboplatin and carboplatin-paclitaxel treatment on tumour volume growth was assessed 1, 2, 4, 7, 11 and 14 days post-treatment. Treated xenografts demonstrated an RTV reduction compared with control samples (Figure 1A). In OV1002 xenografts, both treatments resulted in a clear growth inhibition. Differences were significant at all time points $(P<0.01$; Student's $t$-test) with values diverging from day 1 . The effect peaked at day 7 

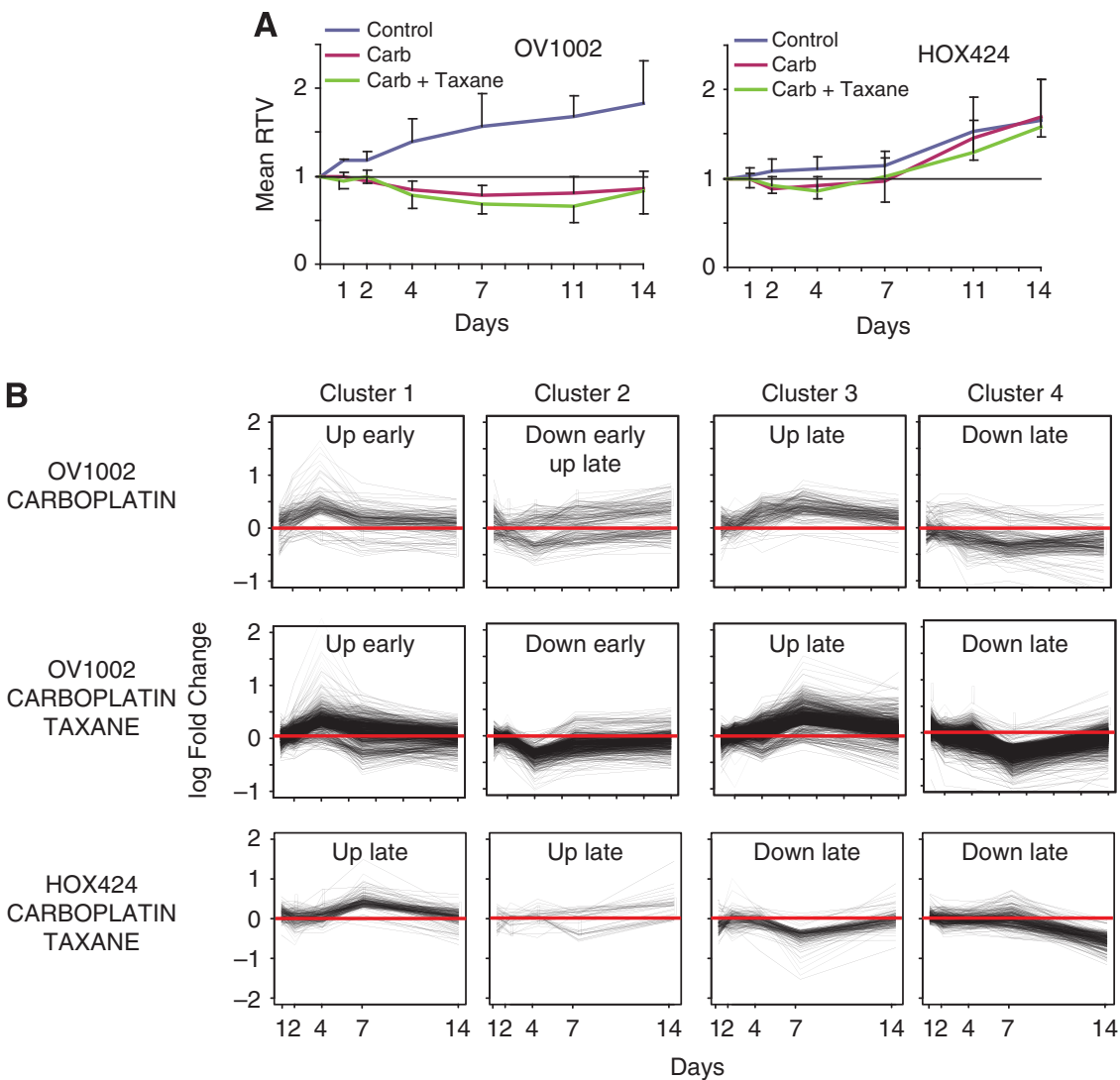

Figure 1. Relative tumour volume (RTV) growth with respect to dynamic gene expression patterns. (A) Post-treatment tumour volume relative to day of treatment (day 0) for the OV1002 and HOX424 xenografts. (B) Mean expression change post-treatment of genes with similar temporal profiles in carboplatin- and carboplatin-paclitaxel-treated OV1002 and in carboplatin-paclitaxel-treated HOX424 xenografts.

for carboplatin or day 11 for carboplatin-paclitaxel, where RTV dropped well below one in treated samples. By day 14, the growth inhibition effect showed signs of reversal. Reduction in RTV was steady and gradual in both groups, although carboplatin-paclitaxel had a larger effect than carboplatin at day $7 \quad(P=0.04)$. Untreated HOX424 samples grew more slowly (Figure 1A). A small growth reduction effect due to both treatment types compared with control was observed, but this was significant only at days $2-7$ (carboplatin, $P<.03$ ) or day 4 (carboplatinpaclitaxel, $P<0.001)$.

Carboplatin dynamically modulates DNA repair, cell cycle and apoptosis control genes in OV1002 xenografts, but has limited effect in gene expression of HOX424. In OV1002 xenografts, a total of 711 genes were differentially expressed mainly late and transiently after carboplatin treatment (Figures 2A and B). A complete listing is shown in Supplementary Table 3, and genes with the largest expression change compared with control are shown in Supplementary Table 4. Several pathways involved in cell cycle control were overrepresented within the pool of differentially expressed genes from all time points, such as cell cycle, DNA replication and p53 signalling (Table 1A, complete pathway statistics in Supplementary Table 5). Hierarchical clustering separated the genes into four main clusters (Figure 1B).

Genes in cluster 1 were mainly upregulated early in treated samples. Many were implicated in cell cycle regulation and DNA repair. Cluster 2 contained genes implicated in apoptosis that were either upregulated or downregulated early and later upregulated. Genes in cluster 3 were mostly upregulated late in treated samples. It contained several genes implicated in the cell cycle and p53 signalling pathways, as well as HIF1 $\alpha$ and its target MET. Cluster 4 genes were mainly downregulated with late expression. This group contained several HIF1 $\alpha$ targets and genes with anti-apoptotic activity (Supplementary Table 6). The results suggest that in OV1002, cell cycle control, DNA repair and pro-apoptotic genes dominated the early response to carboplatin. From day 7, more cell cycle regulators and p53 signalling genes were detected.

In HOX424 xenografts, very few differentially expressed genes were observed upon treatment with carboplatin. Significant genes are shown in Supplementary Table 3 (complete list) and Supplementary Table 7 (largest changes).

Carboplatin-paclitaxel treatment has distinct time-related effects in each ovarian cancer model. In OV1002 xenografts, a total of 3045 genes were differentially expressed upon carboplatinpaclitaxel treatment. The majority of differential genes expressed late and transiently (Figures $2 \mathrm{~A}$ and $\mathrm{B}$ ). Genes with the largest expression change upon treatment are shown in Supplementary Table 8, and a complete list of differentially expressed genes is shown in Supplementary Table 3. Cell proliferation and DNA repair-related pathways such as cell cycle, DNA replication, p53 signalling, nucleotide excision repair, base excision repair, homologous recombination and mismatch repair were overrepresented within differentially expressed genes (Table 1B, complete pathway statistics in Supplementary Table 9). Glutathione metabolism was also significant. Hierarchical clustering separated the genes into four main clusters (Figure 1B).

Genes in cluster 1 were predominantly upregulated early and were implicated in cell cycle control, DNA repair, apoptosis, TGF $\beta$ and Wnt signalling pathways. Cluster 2 genes were generally downregulated early in treated samples. This cluster contained genes implicated in oxidative phosphorylation and citrate cycle, several HIF $1 \alpha$ targets and STAT3, RBL2 and RAB2B. The third cluster contained genes that were mainly upregulated late in 

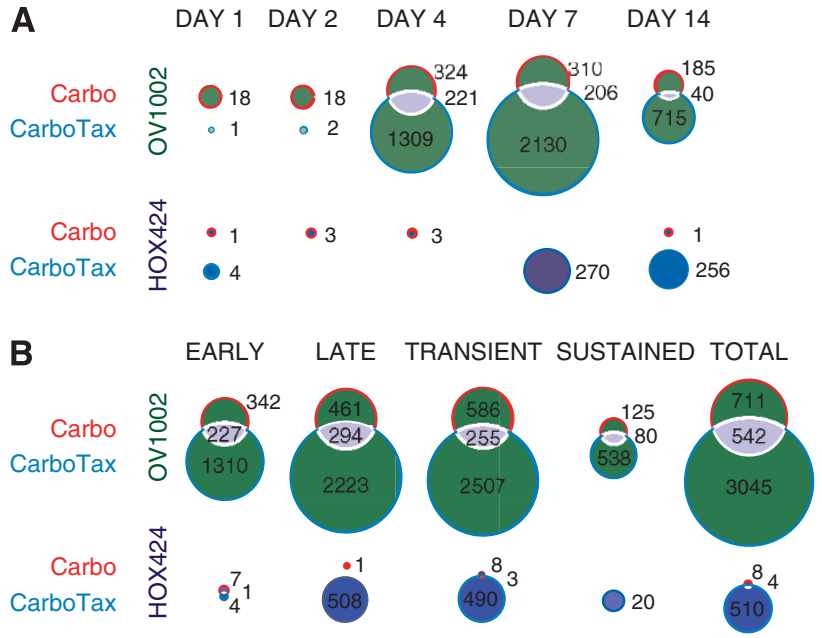

C CLUSTER 1 CLUSTER 2 CLUSTER 3 CLUSTER 4

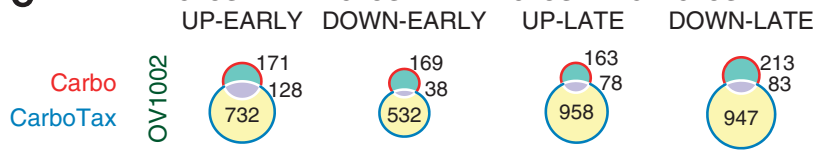

Figure 2. Differential expression analysis of treated OV1002 and HOX424 xenografts. Venn diagrams of differentially expressed gene counts in each time point (A) and according to their temporal characteristics (B) in carboplatin- and carboplatin-taxane-treated OV1002 and HOX424 cells. Gene expression was analysed in 5 time points post-treatment (days 1, 2, 4, 7 and 14). Early (late) genes were differentially expressed in days 1, 2 and 4 (days 7 and 14). Transient (sustained) were differentially expressed in a single time point (more than one time point). (C) Venn diagrams of gene overlaps in each corresponding cluster with similar temporal expression profiles in carboplatin- and carboplatin-paclitaxel-treated OV1002 cells.

treated samples. It included several genes implicated in cell cycle control and p53 signalling and in immune system-related pathways. Other significant genes were members of MAPK and ERBB signalling pathways and PARP9 and PARP10. Genes in cluster 4 were mostly downregulated late and included $H I F 1 \alpha$ targets, some of which were implicated in mTOR signalling. Several heat shock proteins, including several hsp70 species, and Wnt signalling pathway targets were also detected. Other significant genes included DYRK1B, ESR1 and H3F3B (Supplementary Table 6).

In HOX424, there were 510 significant genes with exclusively late/transient expression patterns that were clustered in four groups (Figure 1B and Supplementary Table 3). Genes with the largest expression fold change are shown in Supplementary Table 10. Overrepresented KEGG pathways included apoptosis, Wnt signalling and ribosome pathways (Table 1C and Supplementary Table 9).

Upregulated clusters 1 and 2 were implicated in apoptosis, in cell cycle regulation and other genes with known cancer involvement. Downregulated genes in clusters 3 and 4 were involved in Wnt and MAPK signalling pathways. Other genes in this cluster included HIF1 $\alpha, M S H 2$ and PMS1 (Supplementary Table 6).

These results suggest distinct modes of response to carboplatinpaclitaxel treatment in each ovarian cancer model. In OV1002, the early response was dominated by cell cycle control, DNA repair, pro-apoptotic genes, TGF $\beta$ and Wnt signalling pathways, whereas aerobic metabolic pathways were downregulated. From day 7, more cell cycle regulators, p53 signalling genes, immune system related, MAPK and ERBB pathway genes were detected.
In HOX424, the cell cycle and DNA repair response was limited and late. Instead, several pro-apoptotic genes were induced, whereas Wnt and MAPK signalling pathways were downregulated.

The combined treatment instigated a more extensive response compared with carboplatin alone, judging from the larger count of differentially expressed genes in both xenografts. In OV1002, there was significant overlap of responsive genes between treatments, with 542 genes in common. There was significant overlap among corresponding upregulated groups, especially among the early expressed (Figure 2). Most of the differentially expressed genes in carboplatin-treated xenografts were significant in the combined treatment also, but EME1 (upregulated early), MYC (upregulated late), SIPA1, SIAH1, IGFBP3 and ERCC1 (downregulated) were specific for carboplatin. In carboplatin-paclitaxel-treated OV1002, there were more significant genes within pathways observed in carboplatin-treated cells, but also genes of new pathways altogether (Figure 3).

Dynamic gene expression analysis reveals variation between the two ovarian models in their response to chemotherapeutic agents. When treated xenografts were compared with control samples, more differentially expressed genes were found in OV1002 than in HOX424 after either treatment. There were 206 genes in common between the two xenografts in the combination treatment, of which 143 had the same regulation. For instance, $P A R P 2$ and FANCD2 were positively whereas CASP6, MAPK9 and $B N I P 3 L$ were negatively regulated in both cell lines. A total of 63 genes had opposite regulation (up/down compared with control). Some of these were upregulated in OV1002, such as ETS1, RAPH1, NEK2, MAD2L1, PSMD1, or in HOX424, for instance CAT, HSPA12A, FASTK and WDR6. Pro-apoptotic TNFRSF1A of the MAPK pathway and Wnt pathway modulator SENP2 were upregulated in OV1002, but downregulated in HOX424. Xenografts differed in the time patterns of gene expression, with the chemoresistant HOX424 responding 7 days post-treatment, whereas platinum-sensitive OV1002 demonstrated a more balanced response across time points.

Dynamically changing genes and overrepresented pathways are prognostic of outcome in independent data sets. The relationship to clinical outcome in the clinical ovarian cancer data sets (Supplementary Table 2) was assessed for sets of differentially expressed genes, both for all genes identified from a condition and genes clusters. Gene sets from downregulated late clusters in carboplatin-paclitaxel-treated xenografts were found prognostic of OS in both data sets (Table 2). Other gene sets, such as upregulated late and downregulated early clusters, were successful at differentiating prognosis in one data set.

The relationship to clinical outcome was also assessed for overrepresented pathways. Several overrepresented pathways in the overall set of differentially expressed genes (leftmost columns in Table 1) like oocyte meiosis, apoptosis and cell cycle were prognostic of OS in at least one independent data set. Another seven pathways including Wnt signalling pathway, nucleotide excision repair and focal adhesion were significant predictors $(P<0.05)$ of $\mathrm{OS}$ in one of the two independent data sets. Glutathione metabolism pathway was a significant predictor of OS in both independent data sets. Although all gene members of the cell cycle pathway were prognostic of OS in one data set, subsets of genes found significant in the early upregulated combined treated OV1002 xenografts were prognostic of OS in both data sets. Two pathways in late downregulated gene sets (rightmost columns in Table 1) were prognostic of OS (Table 2): neurotrophin signalling pathway and $\beta$-alanine metabolism (Figure 4). 
Table 1. KEGG pathways overrepresented in dynamically changing genes upon treatment with carboplatin or carboplatin taxane in OV1002 and HOX424 xenografts

A

\section{OV1002 carboplatin}

\section{All differentially expressed genes}

hsa04110: cell cycle

hsa00970: aminoacyl-tRNA

biosynthesis

hsa00240: pyrimidine

metabolism

hsa04115: p53 signalling

pathway

hsa04914: progesterone-

mediated oocyte maturation

hsa04114: oocyte meiosis

hsa00230: purine metabolism

hsa03030: replication

hsa05130: pathogenic

Escherichia coli infection

\begin{tabular}{|l|} 
Cluster 1: up early \\
hsa00970: aminoacyl-tRNA \\
biosynthesis \\
hsa04110: cell cycle \\
hsa00670: one carbon pool by \\
folate \\
hsa00240: pyrimidine \\
metabolism \\
hsa03030: DNA replication
\end{tabular}

Cluster 2: down/up early

Cluster 3: up late

processing and presentation

hsa00240: pyrimidine

metabolism

hsa04623: cytosolic DNA-

sensing pathway hsa04110: cell cycle

hsa04114: oocyte meiosis

hsa04914: progesterone-

mediated oocyte maturation

hsa04115: p53 signalling

pathway

hsa04540: Gap junction
Cluster 4: down late

hsa00051: fructose and

mannose metabolism

hsa00240: pyrimidine

metabolism

B

\section{OV1002 carboplatin-paclitaxe}

\begin{tabular}{|c|c|c|c|c|}
\hline All differentially expressed genes & Cluster 1: up early & Cluster 2: down early & Cluster 3: up late & Cluster 4: down late \\
\hline $\begin{array}{l}\text { hsa03010: ribosome } \\
\text { hsa04110: cell cycle } \\
\text { hsa03030: DNA replication } \\
\text { hsa03420: nucleotide excision } \\
\text { repair } \\
\text { hsa04115: p53 signalling } \\
\text { pathway } \\
\text { hsa00970: aminoacyl-tRNA } \\
\text { biosynthesis } \\
\text { hsa00100: steroid biosynthesis } \\
\text { hsa00240: pyrimidine } \\
\text { metabolism } \\
\text { hsa03410: base excision repair } \\
\text { hsa03430: mismatch repair } \\
\text { hsa00250: alanine, aspartate } \\
\text { and glutamate metabolism } \\
\text { hsa03050: proteasome } \\
\text { hsa05130: pathogenic } \\
\text { Escherichia coli infection } \\
\text { hsa00230:Purine metabolism } \\
\text { hsa00520: amino sugar and } \\
\text { nucleotide sugar metabolism } \\
\text { hsa03440: homologous } \\
\text { recombination } \\
\text { hsa00670: one carbon pool by } \\
\text { folate } \\
\text { hsa00270: cysteine and } \\
\text { methionine metabolism } \\
\text { hsa00051: fructose and } \\
\text { mannose metabolism } \\
\text { hsa00052: galactose metabolism } \\
\text { hsa04612: antigen processing } \\
\text { and presentation } \\
\text { hsa00480: glutathione } \\
\text { metabolism }\end{array}$ & $\begin{array}{l}\text { hsa03030: DNA replication } \\
\text { hsa04110: cell cycle } \\
\text { hsa00970: aminoacyl-tRNA } \\
\text { biosynthesis } \\
\text { hsa00240: pyrimidine } \\
\text { metabolism } \\
\text { hsa03410: base excision repair } \\
\text { hsa03420: nucleotide excision } \\
\text { repair } \\
\text { hsa03430: mismatch repair } \\
\text { hsa00230: purine metabolism } \\
\text { hsa00670: one carbon pool by } \\
\text { folate } \\
\text { hsa04115: p53 signalling } \\
\text { pathway } \\
\text { hsa03440: homologous } \\
\text { recombination } \\
\text { hsa00630: glyoxylate and } \\
\text { dicarboxylate metabolism } \\
\text { hsa00250: alanine, aspartate } \\
\text { and glutamate metabolism } \\
\text { hsa04350: TGF- } \beta \text { signalling } \\
\text { pathway }\end{array}$ & $\begin{array}{l}\text { hsa00020: citrate cycle (TCA } \\
\text { cycle) } \\
\text { hsa00190: oxidative } \\
\text { phosphorylation } \\
\text { hsa04142: lysosome } \\
\text { hsa00280: valine, leucine } \\
\text { and isoleucine degradation } \\
\text { hsa05322: systemic lupus } \\
\text { erythematosus } \\
\text { hsa00100: steroid } \\
\text { biosynthesis } \\
\text { hsa04360: axon guidance }\end{array}$ & $\begin{array}{l}\text { hsa03050: proteasome } \\
\text { hsa04110: cell cycle } \\
\text { hsa04114: oocyte meiosis } \\
\text { hsa05130: pathogenic } \\
\text { Escherichia coli infection } \\
\text { hsa05416: viral myocarditis } \\
\text { hsa05330: allograft rejection } \\
\text { hsa04612: antigen } \\
\text { processing and presentation } \\
\text { hsa04914: progesterone- } \\
\text { mediated oocyte maturation } \\
\text { hsa04115: p53 signalling } \\
\text { pathway } \\
\text { hsa05332: graft-versus-host } \\
\text { disease } \\
\text { hsa04514: cell adhesion } \\
\text { molecules (CAMs) } \\
\text { hsa05320: autoimmune } \\
\text { thyroid disease } \\
\text { hsa04144: endocytosis } \\
\text { hsa04940: type I diabetes } \\
\text { mellitus } \\
\text { hsa04810: regulation of } \\
\text { actin cytoskeleton } \\
\text { hsa04672: intestinal immune } \\
\text { network for lgA production }\end{array}$ & $\begin{array}{l}\text { hsa03010: ribosome } \\
\text { hsa03420: nucleotide } \\
\text { excision repair } \\
\text { hsa00051: fructose and } \\
\text { mannose metabolism } \\
\text { hsa00280: valine, leucine } \\
\text { and isoleucine degradation } \\
\text { hsa00520: amino sugar } \\
\text { and nucleotide sugar } \\
\text { metabolism } \\
\text { hsa00561: glycerolipid } \\
\text { metabolism } \\
\text { hsa04722: neurotrophin } \\
\text { signalling pathway } \\
\text { hsa00650: butanoate } \\
\text { metabolism } \\
\text { hsa03040: spliceosome } \\
\text { hsa00410: } \beta \text {-alanine } \\
\text { metabolism }\end{array}$ \\
\hline
\end{tabular}


Table 1. (Continued)

C

HOX424 carboplatin-paclitaxel

\begin{tabular}{|c|c|c|c|c|}
\hline All differentially expressed genes & Cluster 1: up late (day 7) & Cluster 2: up late (day 14) & Cluster 3: down late (day 7) & Cluster 4: down late (day 14) \\
\hline $\begin{array}{l}\text { hsa03010: ribosome } \\
\text { hsa05130: pathogenic } \\
\text { Escherichia coli infection } \\
\text { hsa05210: colorectal cancer } \\
\text { hsa03040: spliceosome } \\
\text { hsa04210: apoptosis } \\
\text { hsa04530: tight junction } \\
\text { hsa04510: focal adhesion } \\
\text { hsa04662: B-cell receptor } \\
\text { signalling pathway } \\
\text { hsa00450: selenoamino acid } \\
\text { metabolism } \\
\text { hsa00510: N-glycan biosynthesis } \\
\text { hsa04310: Wnt signalling } \\
\text { pathway } \\
\text { hsa05416: viral myocarditis }\end{array}$ & $\begin{array}{l}\text { hsa03010: ribosome } \\
\text { hsa00450: selenoamino acid } \\
\text { metabolism } \\
\text { hsa04210: apoptosis } \\
\text { hsa00460: cyanoamino acid } \\
\text { metabolism } \\
\text { hsa00430: taurine and } \\
\text { hypotaurine metabolism } \\
\text { hsa00590: arachidonic acid } \\
\text { metabolism }\end{array}$ & - & $\begin{array}{l}\text { hsa03010: ribosome } \\
\text { hsa05130: pathogenic } \\
\text { Escherichia coli infection } \\
\text { hsa04510: focal adhesion } \\
\text { hsa04310: Wht signalling } \\
\text { pathway } \\
\text { hsa03050: proteasome }\end{array}$ & $\begin{array}{l}\text { hsa03010: ribosome } \\
\text { hsa03040: spliceosome } \\
\text { hsa05210: colorectal cancer } \\
\text { hsa05130: pathogenic } \\
\text { Escherichia coli infection } \\
\text { hsa05211: renal cell carcinoma } \\
\text { hsa04670: leukocyte } \\
\text { transendothelial migration }\end{array}$ \\
\hline
\end{tabular}

Abbreviations: IgA = immunoglobulin A; KEGG = Kyoto encyclopedia of genes and genomes; TCA = tricarboxylic acid; TGF $\beta=$ transforming growth factor- $\beta$; tRNA = transfer RNA. Pathways are shown for the set of all differentially expressed genes (left column) and for gene sets with similar temporal profiles. (A) Carboplatin-treated OV1002, (B) carboplatin-paclitaxel-treated OV1002 and (C) carboplatin-paclitaxel-treated HOX424.

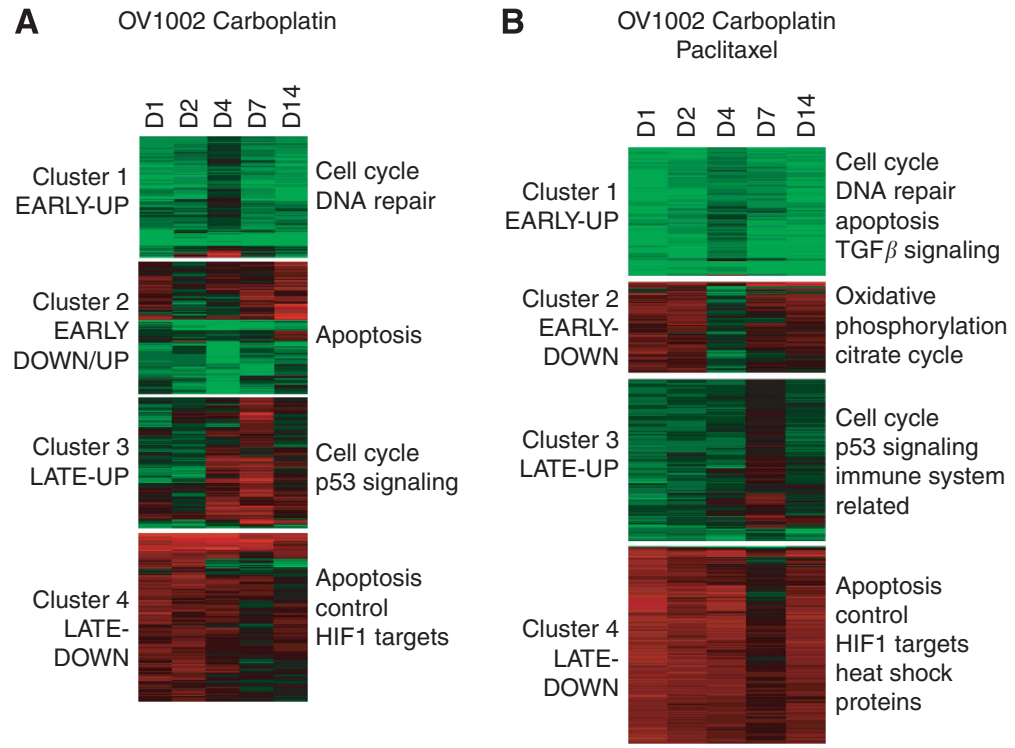
C HOX424 Carboplatin Paclitaxel

Figure 3. Heatmaps of gene sets with significant increased (red) or decreased (green) expression in response to treatment relative to control samples. (A) Carboplatin-treated OV1002, (B) carboplatin-paclitaxel-treated OV1002 and (C) carboplatin-paclitaxel-treated HOX424 xenografts. Clusters are annotated with significant overrepresented functions.

\section{DISCUSSION}

Despite the progress in identification of genes involved in the development of resistance to platinum- and taxane-based chemotherapeutic agents, the exact timing of the transcriptional response post-treatment warrants further research. Two xenograft models with distinct platinum response profiles were used to characterise drug-induced gene expression patterns. This longitudinal study spanned a 14-day period and allowed the analysis of gene expression in multiple time points. Such insight in dynamic expression changes can indicate not only markers associated with platinum sensitivity or resistance, but also the time they become detectable. Clinical snapshots cannot provide such a dynamic view of the transcriptome and may potentially miss informative changes in expression (Taylor et al, 2010).

The two models displayed distinct transcriptional profiles before and after treatment. Up to 4 biological replicates were used for each time point in this study, with high concordance within each condition. A significant RTV effect was observed in the platinumresponsive, high-grade OV1002 xenografts. Early upregulated genes were involved in DNA repair, cell cycle and apoptosis 
Table 2. Prognostic capacity of gene sets with similar temporal expression profiles in three ovarian cancer data sets (log rank $P$-values)

\begin{tabular}{|c|c|c|c|c|}
\hline \multicolumn{2}{|l|}{ Data set } & Bild et al (2006) & \multicolumn{2}{|c|}{ Tothill et al (2008) } \\
\hline \multicolumn{2}{|l|}{ Data set ID } & GSE3149 & \multicolumn{2}{|c|}{ GSE9891 } \\
\hline \multicolumn{2}{|l|}{ Microarray platform } & Affymetrix U133A & \multicolumn{2}{|c|}{ Affymetrix U133 Plus 2} \\
\hline \multicolumn{2}{|l|}{ Samples } & 133 & \multicolumn{2}{|c|}{285} \\
\hline \multicolumn{2}{|l|}{ Platinum/taxane } & & \multicolumn{2}{|c|}{$243 / 195$} \\
\hline Tumour grade $(1 / 2 / 3 / \mathrm{NA})$ & & $3 / 4 / 125 / 1$ & \multicolumn{2}{|c|}{$19 / 97 / 164 / 5$} \\
\hline End point & & OS & os & PFS \\
\hline Gene set & Gene set size & & & \\
\hline All OV1002 carboplatin sets & 711 & 0.0473 & 0.00292 & 0.000642 \\
\hline All OV1002 carboplatin/taxane sets & 3045 & 0.128 & 0.00101 & $2.88 \mathrm{E}-05$ \\
\hline All HOX424 carboplatin/taxane sets & 510 & 0.00931 & 0.000136 & 0.000268 \\
\hline OV1002 carboplatin set 1 up early & 171 & 0.421 & 0.315 & 0.87 \\
\hline OV1002 carboplatin set 2 down/up early & 169 & 0.0406 & 0.062 & 0.00216 \\
\hline OV1002 carboplatin set 3 up late & 163 & 0.577 & 0.112 & 0.059 \\
\hline OV1002 carboplatin set 4 down late & 213 & 0.789 & 0.589 & 0.0935 \\
\hline OV1002 carboplatin/taxane set 1 up early & 733 & 0.0936 & 0.152 & 0.463 \\
\hline OV1002 carboplatin/taxane set 2 down early & 533 & 0.0257 & 0.809 & 0.0304 \\
\hline OV1002 carboplatin/taxane set 3 up late & 958 & 0.263 & 0.008 & $6.48 \mathrm{E}-05$ \\
\hline OV1002 carboplatin/taxane set 4 down late & 947 & 0.0288 & 0.0001 & $4.71 \mathrm{E}-05$ \\
\hline HOX424 carboplatin/taxane set 1 up late & 148 & 0.0285 & 0.468 & 0.469 \\
\hline HOX424 carboplatin/taxane set 2 up late & 27 & 0.869 & 0.065 & 0.532 \\
\hline HOX424 carboplatin/taxane set 3 down late & 119 & 0.0398 & 0.0003 & 0.00126 \\
\hline HOX424 carboplatin/taxane set 4 down late & 226 & 0.000463 & 0.00009 & 0.000102 \\
\hline KEGG apoptosis & 88 & 0.00095 & 0.776 & 0.423 \\
\hline KEGG oocyte meiosis & 114 & 0.647 & 0.00654 & 0.0203 \\
\hline KEGG progesterone-mediated oocyte maturation & 87 & 0.886 & 0.0114 & 0.0847 \\
\hline KEGG p53 signalling pathway & 69 & 0.372 & 0.0139 & $6.40 \mathrm{E}-05$ \\
\hline KEGG cell cycle & 128 & 0.0453 & 0.138 & 0.443 \\
\hline OV1002 carboplatin/taxane cell cycle & 51 & 0.0438 & 0.00814 & 0.00301 \\
\hline OV1002 carboplatin/taxane set 1 up early cell cycle & 25 & 0.0272 & 0.00665 & 0.00683 \\
\hline KEGG glutathione metabolism & 50 & 0.0259 & 0.00895 & 0.726 \\
\hline KEGG neurotrophin signalling pathway & 126 & 0.0282 & 0.00133 & $7.54 \mathrm{E}-06$ \\
\hline KEGG $\beta$-alanine metabolism & 22 & 0.0488 & 0.0414 & 0.000998 \\
\hline
\end{tabular}

regulation, suggesting a driving effect on these pathways immediately after treatment administration. DNA damage-induced apoptosis seems to be responsible for the large RTV reduction in OV1002. In carboplatin-paclitaxel-treated cells, a concurrent downregulation of oxygen-consuming metabolic processes was observed, suggesting a reduction in the metabolic rate and a switch to hypoxic processes. The number of genes was increased in late time points and included downregulated apoptosis inhibitors and heat shock proteins. The RTV effect was gradually reduced in late time points after expression of anti-apoptotic regulators such as aurora kinases and possibly because of hypoxic adaptation. Treatment-based upregulation of $H I F 1 \alpha$ may also be responsible for the gradual RTV reduction observed after day 7 .

Carboplatin uptake triggers activation of DNA repair pathways and, in case damage is beyond repair, cell cycle arrest and apoptosis (Galluzzi et al, 2012). In accordance with this, early response in OV1002 involved DNA repair, cell cycle control and apoptosis genes, which were upregulated in both treatments, with many more in the combined. Several gene functions essential for drug chemosensitivity were observed, providing plausible explanations for the response to treatment by OV1002 and the gradual change to chemoresistance. For instance, CHEK1, which activates branches of MAPK pathway, and CHEK2, shown to convey lethal signals in response to carboplatin (Damia et al, 2001; Pabla et al, 2008), were upregulated in treated xenografts. Several PARPs, including PARP2, PARP6, PARP9 and PARP10, were significant after day 4 , potentially influencing the growth rate during late time points. Downregulation of ERCC1 has been correlated with survival and responsiveness to platinum treatment in various cancers, including ovarian (Dabholkar et al, 1992). This gene was downregulated in carboplatin-treated samples. Early expression of the tumour suppressor XAF1, which antagonises apoptosis inhibitors (Plenchette et al, 2007), was observed in carboplatin-treated xenografts, whereas pro-apoptotic FAS was upregulated in carboplatin-paclitaxel-treated samples. TRIB3, a pro-apoptotic, negative regulator of $A K T 1$ and $N F k B$ that is involved in hypoxia 
A

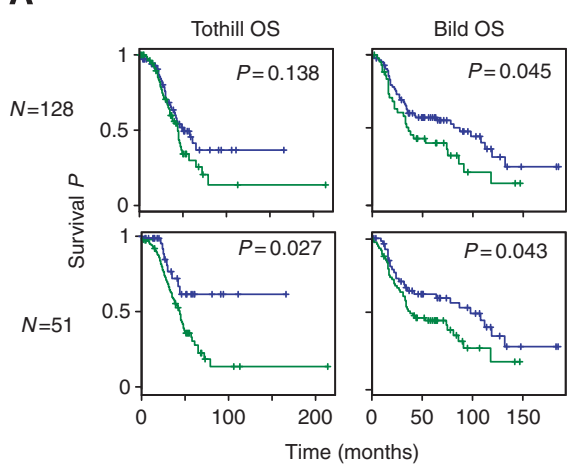

B
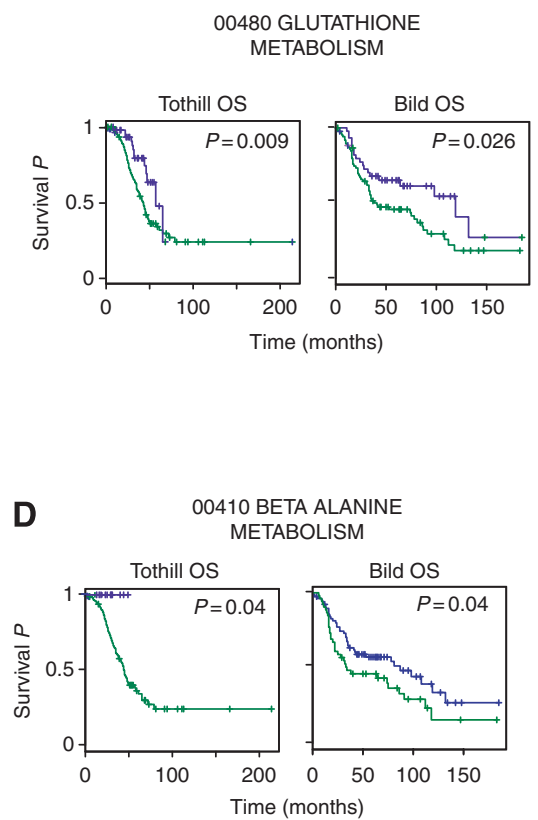

Figure 4. Kaplan-Meier distributions of patient groups clustered according to gene set expression. The KEGG pathway-derived gene sets were prognostic of overall survival in two independent clinical studies (Bild et al, 2006; Tothill et al, 2008). Genes from (A) cell cycle, (B) glutathione metabolism, (C) neurotrophin signalling pathway and (D) $\beta$-alanine metabolism were overrepresented in the carboplatin-paclitaxel-treated OV1002 xenografts. The complete cell cycle pathway $(\mathrm{N}=128)$ gene set was significant in one independent data set, whereas the subset of genes found significant in this study $(N=51)$ was prognostic in both data sets.

response (Wennemers et al, 2011), had the largest expression increase upon both treatments. Heat shock proteins protect against platinum drug activity, thus promoting resistance (Ren et al, 2008). Several heat shock proteins, including hsp70s, were found downregulated in carboplatin-paclitaxel-treated OV1002 xenografts in accordance to the chemoresponsiveness of this cell line.

In the slower growing HOX424, which displays reduced platinum sensitivity, the RTV effect was smaller. Transcriptional response to carboplatin was very limited, suggesting that carboplatin is not internalised in sufficient quantities possibly because of an effective transport mechanism potentially driven by P-type ATPases or ABC transporters. Alternatively, HOX424 may be capable of inactivating carboplatin in the cytoplasm by a glutathione pathway-based mechanism. The response to the combined treatment was exclusively late and contained apoptosis and cell cycle regulators. The modest RTV effect may be attributed to the activation of pro-apoptotic genes (Figure 3). Some, such as FOSB, were not observed in OV1002. The MSH2 downregulation may partly explain the lesser RTV effect in HOX424, as mismatch repair pathway underexpression has been associated with carboplatin resistance (Fink et al, 1998). The effect diminished after day 7 , possibly because of the presence of efficient inherent oxidative stress adaptations and failure to trigger apoptosis.

Taxanes, such as paclitaxel, act by stabilising microtubules, thereby causing a G2-M arrest followed by apoptosis (Shah and Schwartz, 2001). Gene expression differences between treatments may be attributed to paclitaxel addition, yet this was not translated in a dramatic RTV effect. The RTV reduction in carboplatinpaclitaxel compared with carboplatin was significant only in OV1002 day 7. There was substantial overlap between genes and pathways targeted by carboplatin and paclitaxel; however, several known paclitaxel targets, such as TRAF3 (Blagosklonny et al, 1997), were found in OV1002 and many tubulin isotypes in both xenografts.

Both treatments triggered changes in cell cycle pathway at early and late time points, but the response was more comprehensive in carboplatin-paclitaxel treatment. A larger number of cell cycle control genes were expressed late including cyclins, cyclindependent kinases and CDCs, with more expressed after carboplatin-paclitaxel treatment. Many genes affecting G2-M checkpoint were upregulated late after carboplatin-paclitaxel treatment, consistent with the known paclitaxel effect on inhibition of microtubule spindle disassembly.

The two distinct treatment responses of the xenografts provide a measure of interpatient gene expression diversity over time. OV1002 demonstrated the largest RTV reduction and consistently responded to treatment in early time points, whereas HOX424 was growing slower and lacked a sustained RTV reduction effect. The marked variation in the two cell lines may be useful to assess patient responses to new treatment, to investigate mechanisms of drug resistance and possibly to find ways to circumvent it.

Late downregulated genes in both cell lines were associated with prognosis in two clinical data sets. Consistent with their functions, increased expression of SPRY1, CITED2, FZD6 and downregulation of PPFIBP1 were associated with the good prognosis patient clusters. Members of the SPRY family are MAPK inhibitors and RAS antagonists, usually acting as tumour suppressors (Fong et al, 2006; Schaaf et al, 2010). CITED2 interferes with the binding of the transcription factors HIF1 $\alpha$ or STAT2 (Yanagie et al, 2009; Yoon et al, 2011), whereas FZD6 is a negative regulator of the canonical Wnt signalling pathway, acting as an inhibitor of oncogenic transformation and cell proliferation (Golan et al, 2004). PPFIBP1 interacts with $S 100 A 4$, a calcium-binding protein related to tumour invasiveness (Kriajevska et al, 2002). Expression levels of ALDH1A1, ALDH5A1, ALG13, TMEM106B, SPAG16 and $N 4 B P 2 L 1$ were also elevated in good prognosis clusters; however, their involvement in tumourigenesis is not established. Interestingly, elevated SPAG16 has been reported in various tumours (Silinga et al, 2011), whereas N4BP2L1 maps in the region of BRCA2 (13q13.1). Downregulation of these genes coincides with the gradual loss of platinum sensitivity, as seen in the diminishing 
RTV reduction effect after day 7, and may be driving the switch from a responsive to a nonresponsive phenotype (Table 2). Heatmaps in Supplementary Figure 1 indicate the potential value of these genes as biomarkers of outcome.

Several overrepresented pathways identified from the xenografts were found associated with prognosis in the clinical data sets, including the neurotrophin signalling pathway overrepresented in late downregulated genes from OV1002 carboplatin-paclitaxeltreated xenografts. Neurotrophin factors $4 / 5$ are expressed in breast cancer and have been targeted to inhibit breast tumour growth (Vanhecke et al, 2011). Neurotrophin plays a role in the early development of follicles acting via TRKB receptors (Dorfman et al, 2011), and it is plausible that related pathways become dysregulated during tumourigenesis and potentially have prognostic value.

Although the aim of this study is to characterise the dynamic response to platinum drugs and taxanes, rather than assembling a resistance or survival-associated gene signature, several genes from these clusters are promising leads that warrant further investigation. The discovery of gene sets and pathways derived from the late downregulated clusters that were associated with prognosis has been possible only through a dynamic analysis of gene expression over a period of several days. It would be interesting to explore their expression patterns before and after treatment in patients or in additional cell line xenografts.

In this study we demonstrate for the first time that genes responding in a time-related manner to carboplatin-paclitaxel can predict prognosis in primary tumours treated with these chemotherapeutic drugs. Further clinical assessment in pre- and post-treatment tumours from responding or resistant patients will help determine which of those have the potential to be used as predictors of response.

\section{ACKNOWLEDGEMENTS}

We thank Medical Research Scotland and the Scottish Funding Council for supporting this study. We thank the Wellcome Trust Clinical Research Facility in Edinburgh for processing the Illumina Bead chips. We are grateful to In Hwa Um and Charlene Kay for their help in processing the mRNA and protein samples. This work was supported by Medical Research Scotland (FRG353 to VAS), the FP7-Directorate-General for Research and Innovation of the European Commission (EU HEALTH-F4-2012-305033 to Coordinating Action Systems Medicine to DJH); the Chief Scientist Office of Scotland (to DJH) and the Scottish Funding Council (to DJH and SPL).

\section{CONFLICT OF INTEREST}

The authors declare no conflict of interest.

\section{AUTHOR CONTRIBUTIONS}

AK wrote the manuscript and performed all computational analyses; SPL performed all biological experiments; VAS and DJH conceived the study. All authors read and commented on the manuscript and agreed upon a final version together.

\section{REFERENCES}

Bild AH, Yao G, Chang JT, Wang Q, Potti A, Chasse D, Joshi MB, Harpole D, Lancaster JM, Berchuck A, Olson Jr JA, Marks JR, Dressman HK, West M, Nevins JR (2006) Oncogenic pathway signatures in human cancers as a guide to targeted therapies. Nature 439: 353-357.
Blagosklonny MV, Giannakakou P, el-Deiry WS, Kingston DG, Higgs PI, Neckers L, Fojo T (1997) Raf-1/bcl-2 phosphorylation: a step from microtubule damage to cell death. Cancer Res 57: 130-135.

Cannistra SA (2004) Cancer of the ovary. N Engl J Med 351: 2519-2529.

Crijns AP, Fehrmann RS, de Jong S, Gerbens F, Meersma GJ, Klip HG, Hollema H, Hofstra RM, te Meerman GJ, de Vries EG, van der Zee AG (2009) Survival-related profile, pathways, and transcription factors in ovarian cancer. PLoS Med 6: e24.

Dabholkar M, Bostick-Bruton F, Weber C, Bohr VA, Egwuagu C, Reed E (1992) ERCC1 and ERCC2 expression in malignant tissues from ovarian cancer patients. J Natl Cancer Inst 84: 1512-1517.

Damia G, Filiberti L, Vikhanskaya F, Carrassa L, Taya Y, D'incalci M, Broggini M (2001) Cisplatinum and taxol induce different patterns of p53 phosphorylation. Neoplasia 3: 10-16.

Dorfman MD, Kerr B, Garcia-Rudaz C, Paredes AH, Dissen GA, Ojeda SR (2011) Neurotrophins acting via TRKB receptors activate the JAGGED1NOTCH2 cell-cell communication pathway to facilitate early ovarian development. Endocrinology 152: 5005-5016.

Du P, Kibbe WA, Lin SM (2008) Lumi: a pipeline for processing Illumina microarray. Bioinformatics 24: 1547-1548.

Eisen MB, Spellman PT, Brown PO, Botstein D (1998) Cluster analysis and display of genome-wide expression patterns. Proc Natl Acad Sci USA 95: 14863-14868.

Faratian D, Zweemer AJ, Nagumo Y, Sims AH, Muir M, Dodds M, Mullen P, Um I, Kay C, Hasmann M, Harrison DJ, Langdon SP (2011) Trastuzumab and pertuzumab produce changes in morphology and oestrogen receptor signalling in ovarian cancer xenografts revealing new treatment strategies. Clin Cancer Res 17: 4451-4461.

Fink D, Aebi S, Howell SB (1998) The role of DNA mismatch repair in drug resistance. Clin Cancer Res 4: 1-6.

Fong CW, Zhua MS, McKie AB, Ling SH, Mason V, Li R, Yusoff P, Lo TL, Leung HY, So SK, Guy GR (2006) Sprouty 2, an inhibitor of mitogenactivated protein kinase signaling, is down-regulated in hepatocellular carcinoma. Cancer Res 66: 2048-2058.

Galluzzi L, Senovilla L, Vitale I, Michels J, Martins I, Kepp O, Castedo M, Kroemer G (2012) Molecular mechanisms of cisplatin resistance. Oncogene 31: 1869-1883.

Golan T, Yaniv A, Bafico A, Liu G, Gazit A (2004) The human Frizzled 6 (HFz6) acts as a negative regulator of the canonical Wnt $\beta \beta$-catenin signaling cascade. J Biol Chem 279: 14879-14888.

Helleman J, Jansen MP, Span PN, van Staveren IL, Massuger LF, Meijer-van Gelder ME, Sweep FC, Ewing PC, van der Burg ME, Stoter G, Nooter K, Berns EM (2006) Molecular profiling of platinum resistant ovarian cancer. Int J Cancer 118: 1963-1971.

Helleman J, Smid M, Jansen MP, van der Burg ME, Berns EM (2010) Pathway analysis of gene lists associated with platinum-based chemotherapy resistance in ovarian cancer: the big picture. Gynecol Oncol 117: 170-176.

Huang DW, Sherman BT, Lempicki RA (2009) Systematic and integrative analysis of large gene lists using DAVID Bioinformatics Resources. Nat Protoc 4: 44-57.

International Collaborative Ovarian Neoplasm Group (2002) Paclitaxel plus carboplatin versus standard chemotherapy with either single-agent carboplatin or cyclophosphamide, doxorubicin, and cisplatin in women with ovarian cancer: the ICON3 randomised trial. Lancet 360: 505-515.

Kanehisa M, Goto S, Sato Y, Furumichi M, Tanabe M (2012) KEGG for integration and interpretation of large-scale molecular datasets. Nucleic Acids Res 40: D109-D114.

Konstantinopoulos PA, Cannistra SA, Fountzilas H, Culhane A, Pillay K, Rueda B, Cramer D, Seiden M, Birrer M, Coukos G, Zhang L, Quackenbush J, Spentzos D (2011) Integrated analysis of multiple microarray datasets identifies a reproducible survival predictor in ovarian cancer. PLoS One 6: e18202.

Kriajevska M, Fischer-Larsen M, Moertz E, Vorm O, Tulchinsky E, Grigorian M, Ambartsumian N, Lukanidin E (2002) Liprin $\beta 1$, a member of the family of LAR transmembrane tyrosine phosphatase-interacting proteins, is a new target for the metastasis-associated protein S100A4 (Mts1). J Biol Chem 277: 5229-5235.

Li J, Wood 3rd WH, Becker KG, Weeraratna AT, Morin PJ (2007) Gene expression response to cisplatin treatment in drug-sensitive and drugresistant ovarian cancer cells. Oncogene 26: 2860-2872.

Liu J, Campen A, Huang S, Peng SB, Ye X, Palakal M, Dunker AK, Xia Y, Li S (2008) Identification of a gene signature in cell cycle pathway for breast cancer prognosis using gene expression profiling data. BMC Med Genomics 1: 39. 
Pabla N, Huang S, Mi QS, Daniel R, Dong Z (2008) ATR-Chk2 signaling in p53 activation and DNA damage response during cisplatin-induced apoptosis. J Biol Chem 283: 6572-6583.

Plenchette S, Cheung HH, Fong WG, LaCasse EC, Korneluk RG (2007) The role of XAF1 in cancer. Curr Opin Investig Drugs 8: 469-476.

Ren A, Yan G, You B, Sun J (2008) Down-regulation of mammalian sterile 20-like kinase 1 by heat shock protein 70 mediates cisplatin resistance in prostate cancer cells. Cancer Res 68: 2266-2274.

Schaaf G, Hamdi M, Zwijnenburg D, Lakeman A, Geerts D, Versteeg R, Kool M (2010) Silencing of SPRY1 triggers complete regression of rhabdomyosarcoma tumours carrying a mutated RAS gene. Cancer Res 70: 762-771.

Shah MA, Schwartz GK (2001) Cell cycle-mediated drug resistance: an emerging concept in cancer therapy. Clin Cancer Res 7: 2168-2181.

Shahzad MM, Lopez-Berestein G, Sood AK (2009) Novel strategies for reversing platinum resistance. Drug Resist Updat 12: 148-152.

Sherman-Baust CA, Becker KG, Wood Iii WH, Zhang Y, Morin PJ (2011) Gene expression and pathway analysis of ovarian cancer cells selected for resistance to cisplatin, paclitaxel, or doxorubicin. J Ovarian Res 4: 21.

Siliņa K, Zayakin P, Kalniņa Z, Ivanova L, Meistere I, Endzeliņš E, Ābols A, Stengrēvics A, Leja M, Ducena K, Kozirovskis V, Linē A (2011) Spermassociated antigens as targets for cancer immunotherapy: expression pattern and humoral immune response in cancer patients. J Immunother 34: 28-44.

Sims AH, Zweemer AJM, Nagumo Y, Faratian D, Muir M, Dodd M, Um I, Kay C, Hasman M, Harrison DJ, Langdon SP (2012) Defining the molecular response to trastuzumab, pertuzumab and combination therapy in ovarian cancer. Br J Cancer 106: 1779-1789.

Smyth GK (2005) Limma: linear models for microarray data. In Bioinformatics and Computational Biology Solutions Using $R$ and Bioconductor, Gentleman RRW, Carey V, Dudoit S, Irizarry R, Huber Huber WRW (eds) pp 397-420. Springer: New York.

Taylor KJ, Sims AH, Liang L, Faratian D, Muir M, Walker G, Kuske B, Dixon JM, Cameron DA, Harrison DJ, Langdon SP (2010) Dynamic changes in gene expression in vivo predict prognosis of tamoxifen-treated patients with breast cancer. Breast Cancer Res S12: R39.

Tothill RW, Tinker AV, George J, Brown R, Fox SB, Lade S, Johnson DS, Trivett MK, Etemadmoghadam D, Locandro B, Traficante N, Fereday S, Hung JA, Chiew YE, Haviv I. Australian Ovarian Cancer Study GroupGertig D, DeFazio A, Bowtell DD (2008) Novel molecular subtypes of serous and endometrioid ovarian cancer linked to clinical outcome. Clin Cancer Res 14: 5198-5208.

Vanhecke E, Adriaenssens E, Verbeke S, Meignan S, Germain E, Berteaux N, Nurcombe V, Le Bourhis X, Hondermarck H (2011) Brain-derived neurotrophic factor and neurotrophin- $4 / 5$ are expressed in breast cancer and can be targeted to inhibit tumour cell survival. Clin Cancer Res 17: 1741-1752.

Wennemers M, Bussink J, Scheijen B, Nagtegaal ID, van Laarhoven HW, Raleigh JA, Varia MA, Heuvel JJ, Rouschop KM, Sweep FC, Span PN (2011) Tribbles homolog 3 denotes a poor prognosis in breast cancer and is involved in hypoxia response. Breast Cancer Res 13: R82.

Yanagie H, Hisa T, Ogata A, Miyazaki A, Nonaka Y, Nishihira T, Osada I, Sairennji T, Sugiyama H, Furuya Y, Kidani Y, Takamoto S, Takahashi H, Eriguchi M (2009) Improvement of sensitivity to platinum compound with siRNA knockdown of upregulated genes in platinum complexresistant ovarian cancer cells in vitro. Biomed Pharmacother 63: 553-560.

Yoon H, Lim JH, Cho CH, Huang LE, Park JW (2011) CITED2 controls the hypoxic signaling by snatching $\mathrm{p} 300$ from the two distinct activation domains of HIF-1 $\alpha$. Biochim Biophys Acta 1813: 2008-2016.

This work is published under the standard license to publish agreement. After 12 months the work will become freely available and the license terms will switch to a Creative Commons AttributionNonCommercial-Share Alike 3.0 Unported License.

Supplementary Information accompanies this paper on British Journal of Cancer website (http://www.nature.com/bjc) 